\title{
Small-scale variability of benthic macroinvertebrates distribution and its effects on biological monitoring
}

\author{
Alex Laini*, Alessio Vorti, Rossano Bolpagni and Pierluigi Viaroli \\ Department of Life Sciences, University of Parma, Viale G.P. Usberti 33/A - 43124 Parma, Italy
}

Received 2 January 2014; Accepted 28 April 2014

\begin{abstract}
The within-site patchy distribution of organisms represents a natural source of variability that can bias the precision of biotic indices. This study aims to evaluate the spatial distribution of benthic macroinvertebrates and its effects on the biotic index used in Italy for assessing the ecological status of rivers. Two main issues were considered: the sampling design and the minimum number of replicates which are necessary to achieve a given precision level. To this purpose, 30 surber replicates were taken, instead of the ten required for the application of the index, in a homogeneous reach of a mid-sized perennial river (Trebbia River, Northern Italy). The percentile confidence interval (p.c.i.) of the index was calculated from 1000 possible communities with the resampling method and the bootstrap procedure. The $95 \%$ p.c.i. varied from 0.195 to 0.227 , which is great considering that the index ranges from 0 to 1 . The metrics based on abundance data were especially affected by the heterogeneous distribution of organisms. The resulting precision of the index increased only partially when doubling the sampling effort.
\end{abstract}

Key words: Macroinvertebrates / multimetric index / Water Framework Directive / uncertainty / microdistribution

\section{Introduction}

Bioindicators and biological indices are currently used to assess water quality and ecological status of aquatic ecosystems within national and transnational monitoring programs, i.e., the Water Framework Directive in Europe and the Clean Water Act in the USA. Benthic macroinvertebrates have been used especially in rivers, due to their high sensitivity to water quality and pollution. The ability of the indices to distinguish the natural variability from the effects of anthropogenic impacts represents a key issue in order to achieve reliable results for policy and decision making (Niemi and McDonald, 2004).

The confidence and precision of a given biological index are closely linked to the small-scale patchiness of taxa distribution. The spatial variability of macroinvertebrates distribution represents a potential source of the index variation that cannot be easily minimized (Boyero and Bailey, 2001; Li et al., 2001). The within-site variability is the main source of variation in terms of taxa richness (Heino et al., 2004), which depends on multiple factors such as species interaction (Woodward, 2009), resource availability (Culp et al., 1983; Fenoglio et al., 2005), hydrological heterogeneity (Bournaud et al., 1998;

\footnotetext{
*Corresponding author: alex.laini@unipr.it
}

Brooks et al., 2005) and disturbance (Lake, 2000). The actual methods are not designed to capture the small scale variability of the macroinvertebrate distribution (Woodward et al., 2010), although valuable efforts were made in order to quantify this source of uncertainty (Clarke and Hering, 2006; Vlek et al., 2006).

We hypothesized that the patchy and heterogeneous distribution of macroinvertebrates may result in an excessive variability of the biological indices. For this reason, we started a study aiming to evaluate the effects of microscale distribution of benthic macroinvertebrates on the STAR_ICMi, the index adopted in Italy for the classification of river ecological status (Buffagni and Erba, 2007). In particular, we aimed (a) to evaluate the effect of the sampling design on the ecological status classification expressed by the STAR_ICMi index and (b) to identify the minimum replicates number required to achieve a given index precision.

\section{Material and methods}

Sampling was carried out in August 2013 in the Trebbia River, a perennial tributary of the Po River with a mean annual discharge of nearly $21 \mathrm{~m}^{3} \mathrm{~s}^{-1}$ and a total 
length of $118 \mathrm{~km}$. The study reach $\left(44^{\circ} 55^{\prime} 32.35^{\prime \prime} \mathrm{N}\right.$; $9^{\circ} 35^{\prime} 27.56^{\prime \prime} \mathrm{E}$ ), is considered a "reference site" sensu WFD for the fluvial type SS4 (Hydroecoregion 06, Po Valley) with a mean discharge during summer of $5.2 \mathrm{~m}^{3} \mathrm{~s}^{-1}$ (from 2003 to 2011; www.arpa.emr.it). At the sampling time, river's channel width and mean depth were nearly 67 and $0.2 \mathrm{~m}$, respectively. The sampling reach was composed of four different microhabitats: 50\% mesolithal (MES), 40\% microlithal (MIC), 5\% macrolithal (MAC) and 5\% algae (ALG). Overall, the mesohabitat type was considered as generic, since the riffle-pool sequence was indistinguishable.

As prescribed by the national protocols macroinvertebrates were sampled using a multihabitat sampling procedure that requires proportional allocation of the replicates across the most represented habitat types at the site (Buffagni and Erba, 2007). Sampling effort and taxonomic resolution vary with respect to river typology and sampling method; for the Hydroecoregion 6 the samples have to be taken with a surber net in riffle or pool mesohabitats for a total investigated area of $0.5 \mathrm{~m}^{2}$. Using a surber net with a delimiting area of $0.05 \mathrm{~m}^{2}$, the standard procedure requires the placement of ten sampling units proportional to the abundance of the different microhabitat type. Thirty sampling units were collected instead of the ten required by the STAR_ICMi method. Based on the coverage percentage of microhabitats, the 30 replicates were distributed as follows: 12 in MES, 12 in MIC, 3 in MAC and 3 in ALG. The sampling units were randomly chosen along six transect ( $5 \mathrm{~m}$ width) separated by a distance of $10 \mathrm{~m}$. Each replicate was kept separated from the others and collected in PET bottle. The sorting and classification were performed on site to the family level according to Campaioli et al. $(1994,1998)$. A subset of the organisms sorted on site was preserved in $70 \%$ ethanol and classified under a Leica S8AP0 Stereomicroscope (Leica Microsystems, Wetzlar, Germany).

\section{Data analysis}

Non-metric multidimensional scaling (nMDS) was used in order to test the importance of microhabitat in structuring the macroinvertebrates community. This analysis was applied to the entire dataset, with the BrayCurtis as dissimilarity measure and the stress measure to evaluate the goodness of fit (Legendre and Legendre, 1998). Since the abundance of different taxa was highly variable, data were transformed with the square root after a Wisconsin double standardization (Bray and Curtis, 1957).

The variability of the index with respect to macroinvertebrate microdistribution was assessed by means of resampling methods. Ten replicates, corresponding to a total area of $0.5 \mathrm{~m}^{2}$, were randomly chosen without replacement from the 30 available and the abundances of each family summed in order to construct a series of 1000 possible communities. The random choice of the replicates was conditional to the coverage percentage of habitat type in the river. For example for a specific microhabitat type with $40 \%$ of coverage and 12 replicates sampled only four replicates were chosen. Once the 1000 communities were constructed the STAR_ICMi index was calculated using the software Macroper version 0.1.1 (Buffagni et al., 2008) and the percentile confidence interval (p.c.i.) was subsequently calculated (Efron and Tibshirani, 1993). The STAR_ICMi index was calculated for both riffle and pool mesohabitats for which the reference values are present. Since the STAR_ICMi allows only one replicate for microhabitat with coverage $<10 \%$, two series of possible communities were built with five replicates for MES, four for MIC and one for MAC or ALG. The 1000 constructed communities represent a subset of the possible real combination of replicates that can be realized during a monitoring campaign.

The STAR_ICMi is a multimetric index composed by six metrics: Average Score Per Taxon (ASPT), logarithm of the abundance of the selected families of Ephemeroptera, Plecoptera, Trichoptera and Diptera $(\log ($ sel_EPTD +1$))$, total number of taxa, number of EPT taxa, 1 minus the relative abundance of Gastropoda, Oligochaeta and Diptera (1-GOLD) and the Shannon index. The taxonomic resolution needed for the calculation of the STAR_ICMi is the family level. Once the metrics are calculated they are normalized with the reference community values and weighted. The values obtained are summed and the sum normalized with the value of the reference community. The reference values for STAR_ICMi and its metrics are reported in the ministerial decree DM 260/2010.

In order to evaluate the number of replicates needed to achieve a predetermined error a bootstrap method was used. From 1 to 20 replicates, normalized for $1 \mathrm{~m}^{2}$, were chosen randomly with replacement from the 30 replicates available. For each number of replicates the random choice was repeated 1000 times and the p.c.i. was calculated. The macroinvertebrate communities for assessing the sampling effort were built regardless of the microhabitat type from which the replicates were chosen, since the nMDS did not show clusters related to any particular microhabitat type. Moreover, the coefficient of variation $(\mathrm{CV})$ was calculated for the single metrics composing the STAR_ICMi index.

All analyses were performed with the base and vegan packages (Oksanen et al., 2013) of the statistical software R (R Core Team, 2013).

\section{Results}

\section{Community structure}

During the survey, 1709 organisms were collected and a total of 25 families were identified. The measure of stress of the nMDS calculated over three axes was 0.12 , lower than the value of 0.20 , the maximum value for having a reliable ordination (Clarke, 1993). The structure of macroinvertebrate community was not severely affected by the microhabitat from which organisms were collected 


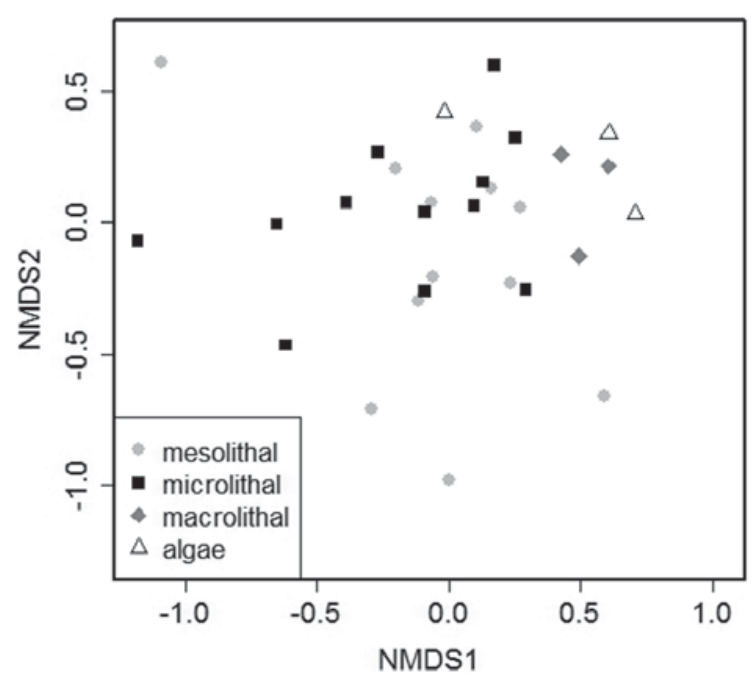

Fig. 1. Non-metric multidimensional scaling plot in which each point represents a single replicate collected in the Trebbia River (stress $=0.12$ ).

as distinct clusters of point cannot be clearly identified from the nMDS ordination plot (Fig. 1).

\section{Influence of macroinvertebrate microdistribution on the STAR_ICMi index}

Each series of resampled communities ( 2 mesohabitat $x$ 2 rare microhabitat) consists of 1000 possible communities for which the median value and the 2.5 and 97.5 percentiles of the STAR_ICMi index were calculated (Table 1). The p.c.i. for the communities MES + MIC + MAC was 0.209 for pool and 0.227 for riffle mesohabitats. The p.c.i. for MES + MIC + ALG was 0.195 for pool and 0.212 for riffle mesohabitats. The ecological status of the constructed communities is also reported in Table 1.

\section{Assessment of the sampling effort needed to achieve reliable results}

Table 2 reports median values and 2.5 and 97.5 percentiles for the STAR_ICMi calculated for an increasing sampling effort. Results from pool and riffle mesohabitats were similar; therefore, only pool data are presented.
The effects of the increasing sampling effort on the metric values are reported in Table 3. The metrics 1-GOLD and Shannon index attained high $\mathrm{CV}$ also at the maximum sampling effort: 39 and $21 \%$, respectively. At the maximum sampling effort ASPT $(\mathrm{CV}=3 \%)$, total number of families $(\mathrm{CV}=6 \%)$, number of EPT families $(\mathrm{CV}=9 \%)$ and the $\log$ of selected EPTD $(\mathrm{CV}=9 \%)$ were affected by a much lower variability.

\section{Discussion}

The structure of the macroinvertebrate community was not severely affected by the microhabitat composition of the considered site (Fig. 1). Likely, the distribution and assemblages of the macroinvertebrates were not affected by the substratum typology. Indeed, the dependence of community structure on substratum typology and grain size is a controversial issue, although diversity and abundances often depend on grain size (Barnes et al., 2013). The taxonomic composition and abundances recorded in the algal microhabitat were not clearly different from those recorded in the mineral substratum (Fig. 1). This is probably an effect of the taxon composition and abundance of the algal assemblages, which at the sampling time were not sufficiently developed to modify the macroinvertebrate community with respect to the mineral substrates. However, further investigations and the use of formal statistical tests are needed in order to clarify the effects of the grain size in determining the community structure of macroinvertebrates.

This study demonstrates that the within-site variability of the STAR_ICMi index was high, although the ecological status was not severely affected by this variability. The p.c.i. of the STAR_ICMi index varied from 0.195 (microhabitat ALG and mesohabitat pool) to 0.227 (microhabitat MAC and mesohabitat riffle). The latter was quite similar to the class interval used for the attribution of the ecological status $(\sim 0.24)$. The ecological status of the site was not affected by this variability, since the value of good status was the most frequent (Table 1). This is particularly true for the calculation made with the reference community of the mesohabitat pool (mean values of 0.829 and 0.843 for ALG and MAC, respectively) for which the value of the STAR_ICMi index approached the mean value of the good status class interval (0.82). As a consequence nearly $95 \%$ of the results falls in the good status (Table 1). The ecological status calculated with the reference community of the

Table 1. Median, 2.50 and 97.50 percentiles values of the STAR_ICMi calculated on the 1000 resampled communities. Calculations were made considering both riffle and pool mesohabitats, while both algae (ALG) and macrolithal (MAC) were used as the residual replicates. High, good and sufficient refer to the number of replicates falling in the corresponding ecological status classes.

\begin{tabular}{|c|c|c|c|c|c|c|c|}
\hline Mesohabitat & Microhabitat & Median & $2.50 \%$ & $97.50 \%$ & High & Good & Sufficient \\
\hline$\overline{\text { Pool }}$ & ALG & 0.829 & 0.732 & 0.927 & 10 & 984 & 6 \\
\hline Riffle & ALG & 0.893 & 0.788 & 1.000 & 228 & 772 & 0 \\
\hline Pool & MAC & 0.843 & 0.734 & 0.943 & 41 & 957 & 2 \\
\hline Riffle & MAC & 0.908 & 0.792 & 1.019 & 330 & 670 & 0 \\
\hline
\end{tabular}


Table 2. Median, 2.5 and 97.5 percentile values of the STAR_ICMi calculated on the 1000 bootstrapped communities constructed for each sampling effort. Minimum (min) and maximum $(\max )$ values are also reported. N, number of replicates; p.c.i., percentile confidence interval; $\mathrm{CV}$, coefficient of variation.

\begin{tabular}{|c|c|c|c|c|c|c|c|}
\hline $\bar{N}$ & $\min$ & $2.5 \%$ & $50 \%$ & $97.5 \%$ & $\max$ & p.c.i. & $\overline{\mathrm{CV}}$ \\
\hline 1 & 0.312 & 0.312 & 0.660 & 0.971 & 0.971 & 0.659 & $\overline{21}$ \\
\hline 2 & 0.312 & 0.470 & 0.776 & 0.968 & 1.018 & 0.498 & 16 \\
\hline 3 & 0.322 & 0.497 & 0.798 & 0.958 & 1.030 & 0.461 & 14 \\
\hline 4 & 0.445 & 0.578 & 0.808 & 0.962 & 1.017 & 0.384 & 12 \\
\hline 5 & 0.473 & 0.604 & 0.820 & 0.953 & 1.003 & 0.349 & 10 \\
\hline 6 & 0.511 & 0.676 & 0.833 & 0.959 & 1.005 & 0.283 & 8 \\
\hline 7 & 0.505 & 0.699 & 0.832 & 0.967 & 1.024 & 0.268 & 9 \\
\hline 8 & 0.561 & 0.704 & 0.842 & 0.957 & 1.019 & 0.253 & 9 \\
\hline 9 & 0.581 & 0.723 & 0.843 & 0.958 & 0.997 & 0.235 & 7 \\
\hline 10 & 0.555 & 0.729 & 0.847 & 0.960 & 1.000 & 0.231 & 7 \\
\hline 11 & 0.641 & 0.730 & 0.849 & 0.955 & 0.995 & 0.225 & 7 \\
\hline 12 & 0.663 & 0.743 & 0.854 & 0.957 & 0.998 & 0.214 & 6 \\
\hline 13 & 0.619 & 0.744 & 0.857 & 0.960 & 0.990 & 0.216 & 7 \\
\hline 14 & 0.664 & 0.762 & 0.860 & 0.959 & 0.994 & 0.197 & 6 \\
\hline 15 & 0.674 & 0.759 & 0.861 & 0.960 & 0.984 & 0.201 & 5 \\
\hline 16 & 0.658 & 0.760 & 0.862 & 0.952 & 0.989 & 0.192 & 5 \\
\hline 17 & 0.675 & 0.769 & 0.865 & 0.960 & 0.991 & 0.191 & 5 \\
\hline 18 & 0.714 & 0.772 & 0.868 & 0.953 & 0.995 & 0.181 & 5 \\
\hline 19 & 0.708 & 0.771 & 0.868 & 0.952 & 0.978 & 0.181 & 6 \\
\hline 20 & 0.706 & 0.781 & 0.870 & 0.948 & 0.985 & 0.167 & 5 \\
\hline
\end{tabular}

Table 3. Coefficient of variation of the metrics composing STAR_ICMi calculated on the 1000 bootstrapped communities constructed for each sampling effort. N, number of replicates; ASPT, average score per taxon; EPT, Ephemeroptera, Plecoptera, Trichoptera; 1-GOLD, 1 minus the relative abundance of Gastropoda, Oligochaeta and Diptera; $\log (\mathrm{sel}$ EPTD + 1): logarithm of the abundance of the selected families of Ephemeroptera, Plecoptera, Trichoptera and Diptera. See the Material and methods section for more details.

\begin{tabular}{|c|c|c|c|c|c|c|}
\hline $\bar{N}$ & ASPT & No. of families & No. of EPT families & 1-GOLD & Shannon index & $\log (\operatorname{sel}($ EPTD $)+1)$ \\
\hline 1 & 12 & 36 & 36 & 32 & 36 & 100 \\
\hline 2 & 8 & 23 & 25 & 43 & 32 & 60 \\
\hline 3 & 7 & 20 & 23 & 53 & 35 & 37 \\
\hline 4 & 5 & 16 & 19 & 46 & 29 & 38 \\
\hline 5 & 4 & 14 & 18 & 48 & 32 & 23 \\
\hline 6 & 4 & 12 & 13 & 42 & 24 & 24 \\
\hline 7 & 4 & 10 & 14 & 42 & 25 & 21 \\
\hline 8 & 4 & 11 & 15 & 50 & 28 & 19 \\
\hline 9 & 3 & 10 & 14 & 38 & 21 & 12 \\
\hline 10 & 3 & 9 & 12 & 39 & 22 & 14 \\
\hline 11 & 3 & 8 & 12 & 41 & 23 & 14 \\
\hline 12 & 3 & 9 & 12 & 39 & 22 & 12 \\
\hline 13 & 3 & 7 & 10 & 41 & 23 & 11 \\
\hline 14 & 3 & 8 & 11 & 36 & 21 & 10 \\
\hline 15 & 3 & 7 & 10 & 36 & 20 & 10 \\
\hline 16 & 3 & 6 & 9 & 36 & 19 & 9 \\
\hline 17 & 3 & 7 & 9 & 36 & 20 & 10 \\
\hline 18 & 3 & 7 & 10 & 36 & 19 & 10 \\
\hline 19 & 3 & 6 & 9 & 38 & 22 & 9 \\
\hline 20 & 3 & 6 & 9 & 39 & 21 & 9 \\
\hline
\end{tabular}

mesohabitat riffle was more variable, since the median values of STAR_ICMi index were far from the mean value of the good status class interval (0.893 and 0.908 for ALG and MAC, respectively). With the reference community of the mesohabitat riffle the ecological status were judged good in 77 and $67 \%$ of the cases for microhabitat ALG and MAC, respectively (Table 1). In the case of Trebbia
River the choice of the rare microhabitat did not affect the calculation of the ecological status (Table 1).

The metrics composing the STAR_ICMi index have different responses to the random choice of the replicates (Table 3). Metrics such as ASPT and the total number of families show an acceptable CV $(<10 \%)$ with a sampled area of $0.5 \mathrm{~m}^{2}$ (ten replicates). Total EPT families and 
$\log$ of selected EPTD show a $\mathrm{CV}<10 \%$ with a sampled area of $\sim 0.75 \mathrm{~m}^{2}$, whereas Shannon index and 1-GOLD never show a $\mathrm{CV}<20 \%$. The last two metrics are affected by great variability, probably because they are calculated from the abundance data. The patchiness of Simuliidae distribution, with abundances ranging from 0 to 864 ind. $\mathrm{m}^{-2}$, could explain the behavior of these metrics. Although based on abundances the metric $\log (\mathrm{sel}$ EPTD + 1) has CV $<10 \%$ with a sampling effort $0.7 \mathrm{~m}^{2}$, likely due to the logarithm transformation. A major influence of abundances on variability of some biological metrics was found also by Vlek et al. (2006). The sampling effort required to minimize the confidence interval is quite difficult to identify, due to the dataset available and the multimetric structure of the index. However, the bootstrap approach used in this work allowed us to evaluate the index variability at different sampling efforts. Since the index should be bounded in the $0-1$ interval, the p.c.i. can be turned into a percentage. This percentage, calculated for a sampling effort corresponding to the exploration of the standard area $\left(0.5 \mathrm{~m}^{2}\right)$, is nearly $23 \%$ in agreement with the results of the previous analyses about the influence of macroinvertebrate distribution on STAR_ICMi index, while doubling the sampling effort $\left(1 \mathrm{~m}^{2}\right)$ allows reducing the percentage to $17 \%$ (Table 3 ). Since the decrease of the confidence interval percentages follows an exponential decay, the sampling effort needed to achieve percentages lower than $10 \%$ is high. It should be noticed that the p.c.i. provides quite different information with respect to the $\mathrm{CV}$, since p.c.i $=17 \%$ is equivalent to a $\mathrm{CV} \sim 5 \%$ (Table 3). Therefore the evaluation of the index performances is a critical task.

Overall, the variability of the STAR_ICMi index is dependent on the correct evaluation of both taxa richness and abundance of macroinvertebrates. In this frame, the present approach could be useful in order to evaluate this source of uncertainty. Furthermore, an extra source of variability is represented by the reference community itself that was considered fixed in this work. In this context, the study of the propagation of uncertainty represents almost an obligatory procedure to properly assess the precision of multimetric indices. Summarizing, the approach used in this work is time consuming but it allows validation of the metrics in use for the ecological assessment of rivers as well as significantly improve the quality of the information gathered.

Despite the small dataset available, this work highlights the occurrence of bias for biological indices caused by the natural variability of the macroinvertebrates distribution. Since biotic indices are used as a scientific tool for supporting policy and decision making, this is a challenging issue to achieve a reliable water quality assessment.

Acknowledgements. The authors wish to thank Dr M. Bartoli, Dr S. Guareschi and two anonymous reviewers for the valuable suggestions. A. Laini was supported by a grant from Consorzio dell'Oglio, R. Bolpagni was supported by a grant from
Emilia-Romagna Region (provided by Regional Rural Development Program 2007-2013, measure 323).

\section{References}

Barnes J.B., Vaughan I.P. and Ormerod S.J., 2013. Reappraising the effects of habitat structure on river macroinvertebrates. Freshw. Biol., 58, 2154-2167.

Bournaud M., Tachet H., Berly A. and Cellot B., 1998. Importance of microhabitat characteristics in the macrobenthos microdistribution of a large river reach. Ann. Limnol. - Int. J. Lim., 34, 83-98.

Boyero L. and Bailey R.C., 2001. Organization of macroinvertebrate communities at a hierarchy of spatial scales in a tropical stream. Hydrobiologia, 464, 219-225.

Buffagni A. and Erba S., 2007. Macroinvertebrati acquatici e Direttiva 2000/60/EC (WFD) - Parte A. Metodo di campionamento per i fiumi guadabili. IRSA-CNR Notiziario dei Metodi Analitici, 1, 2-27.

Buffagni A., Erba S. and Pagnotta R., 2008. Definizione dello Stato ecologico dei fiumi sulla base dei macroinvertebrati bentonici per la 200/60/EC (WFD): il sistema di classificazione MacrOper per il monitoraggio operativo. IRSA-CNR Notiziario dei Metodi Analitici, 1, 24-46.

Bray J.R. and Curtis J.T., 1957. An ordination of the upland forest communities of southern Wisconsin. Ecol. Monogr., 27, 325-349.

Brooks A.J., Haeusler T.I.M., Reinfelds I. and Williams S., 2005. Hydraulic microhabitats and the distribution of macroinvertebrate assemblages in riffles. Freshw. Biol., 50, 331-344.

Campaioli S., Ghetti P.F., Minelli A. and Ruffo S., 1994. Manuale per il riconoscimento dei macroinvertebrati delle acque dolci italiane Volume 1, Edizione del Museo di Storia Naturale di Trento, $357 \mathrm{p}$.

Campaioli S., Ghetti P.F., Minelli A. and Ruffo S., 1998. Manuale per il riconoscimento dei macroinvertebrati delle acque dolci italiane Volume 2, Edizione del Museo di Storia Naturale di Trento, 135 p.

Clarke K.R., 1993. Non-parametric multivariate analyses of changes in community structure. Aust. J. Ecol., 18, 117-143.

Clarke R.T. and Hering D., 2006. Errors and uncertainty in bioassessment methods - major results and conclusions from the STAR project and their application using STARBUGS. Hydrobiologia, 566, 433-439.

Culp J.M., Walde S.J. and Davies R.W., 1983. Relative importance of substrate particle size and detritus to stream benthic macroinvertebrate microdistribution. Can. J. Fish Aquat. Sci., 40, 1568-1574.

Efron B. and Tibshirani R.J., 1993. An Introduction to the Bootstrap, Chapman \& Hall, New York, 456 p.

Fenoglio S., Bo T., Agosta P. and Malacarne G., 2005. Temporal and spatial patterns of coarse particulate organic matter and macroinvertebrate distribution in a low-order Apennine stream. J. Freshw. Ecol., 20, 539-547.

Heino J., Louhi P. and Muotka T., 2004. Identifying the scales of variability in stream macroinvertebrate abundance, functional composition and assemblage structure. Freshw. Biol., 49, 1230-1239. 
Lake P.S., 2000. Disturbance, patchiness, and diversity in streams. J. N. Am. Benthol. Soc., 19, 573-592.

Legendre P. and Legendre L., 1998. Numerical Ecology, (2nd edn), Elsevier Scientific, Amsterdam, 853 p.

Li J., Herlihy A., Gerth W., Kaufmann P., Gregory S., Urquhart S. and Larsen D.P., 2001. Variability in stream macroinvertebrates at multiple spatial scales. Freshw. Biol., 46, 87-97.

Niemi G.J. and McDonald M.E., 2004. Application of ecological indicators. Annu. Rev. Ecol. Evol. S., 35, 89-111.

Oksanen J., Guillaume Blanchet F., Kindt R., Legendre P., Minchin P.R., O’Hara R.B., Simpson G.L., Solymos P., Henry M., Stevens H. and Wagner H., 2013. vegan: Community Ecology Package. R package version 2.0-8. http://CRAN.R-project.org/package = vegan.
R Core Team, 2013. R: A language and environment for statistical computing. $\mathrm{R}$ Foundation for Statistical Computing, Vienna, Austria. URL http://www.R-project. org/.

Vlek H.E., Šporka F. and Krno I., 2006. Influence of macroinvertebrates sample size in bioassessment of stream. Hydrobiologia, 566, 523-542.

Woodward G., 2009. Biodiversity, ecosystem functioning and food webs in freshwaters: assembling the jigsaw puzzle. Freshw. Biol., 54, 2171-2187.

Woodward G., Friberg, N. and Hildrew A.G., 2010. Science and non-science in the biomonitoring and conservation of fresh waters. In: de Carlo F. and Bassano A. (ed.), Freshwater Ecosystems and Aquaculture Research, Nova Science, Hauppauge, NY, USA, 277-288. 